\title{
Chaotic dynamics underpins the slow oscillation of general anesthesia and nonREM sleep
}

Moira L Steyn-Ross ${ }^{1 *}$, D Alistair Steyn-Ross ${ }^{1}$, Jamie W Sleigh ${ }^{2}$

From Twenty First Annual Computational Neuroscience Meeting: CNS*2012

Decatur, GA, USA. 21-26 July 2012

Electrical recordings of brain activity show that entry into anesthetic unconsciousness is signposted by the emergence of large, slow oscillations of electrical activity $(\sim 1 \mathrm{~Hz})$ that appear very similar to the slow waves observed in natural sleep. In this phase, populations of cortical neurons periodically switch between hyperpolarized inactivity ("down" state), and wake-like depolarized activation ("up" state) [1]. The origin of the slow oscilla-
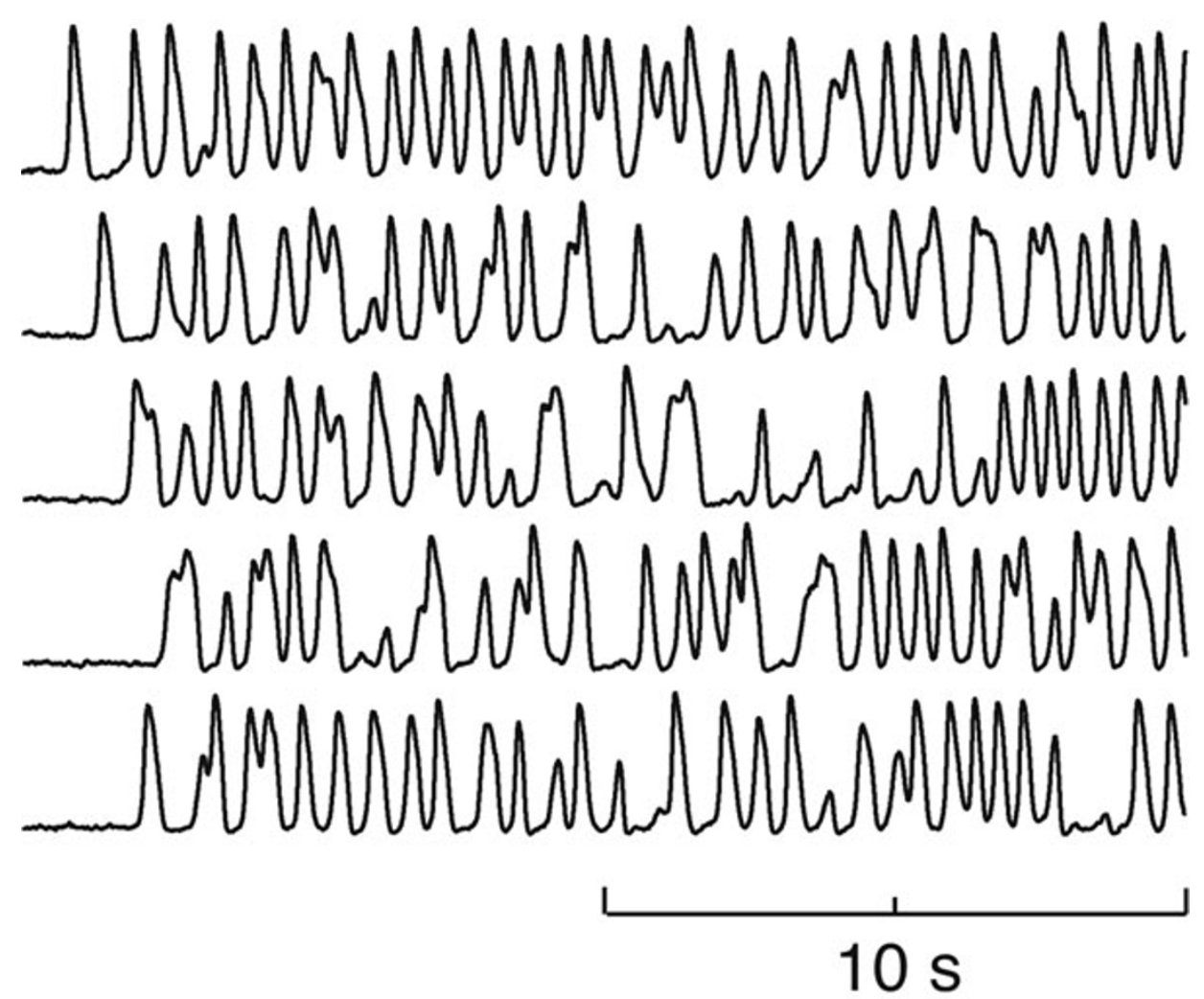

Figure 1 Spontaneous slow-wave oscillations in cortical firing-rate patterns during $20 \mathrm{~s}$ of simulated anesthesia. Traces were recorded from five equally-spaced points lying along the midline of the $25-\times 25-\mathrm{cm}$ simulated cortical grid. Time-series are chaotic in space and time.

\footnotetext{
* Correspondence: msr@waikato.ac.nz

${ }^{1}$ School of Engineering, University of Waikato, Hamilton 3240, New Zealand

Full list of author information is available at the end of the article
} 
tion has not yet been unambiguously established, and remains an area of intense research and debate $[2,3]$. Here we suggest a novel mechanism in which the upand down-states are generated spontaneously by emergent chaotic waves of spatiotemporal activity that sweep the cortex. We present a mean-field model of the cortex in which populations of neurons are densely interlinked by both chemical synapses-including idealized longrange spatially heterogeneous connections-and by direct electrical connections forming a continuous network of interneuronal gap junctions. Anesthetic effect is modeled as a moderate reduction in inhibitory diffusion, paired with an increase in inhibitory postsynaptic potential. We explore model dynamics in the vicinity of a general-anesthetic induced transition from wake to coma. In this region the system is poised at a codimension-2 point where competing Turing (spatial) and Hopf (temporal) instabilities co-exist. We argue that normal functioning of the resting "default-wake" brain requires a delicate balance between these instabilities. Reduction of gap-junction diffusivity disturbs the balance in favor of the Hopf instability, eventually predicting global seizure in the limit of severe imbalance.

Our cortical model predicts that introduction of anesthetic to the awake brain will force a subtle rebalancing of dynamic pressures resulting in a coma state that is characterized by emergent low-frequency oscillations whose dynamics is chaotic in time and space: see Fig. 1. We quantify cortical dynamics in terms of a phase coherence measure and demonstrate that the modelpredicted turbulent slow-wave state is characterized by low phase coherence. This prediction is supported by clinical studies of phase synchronization changes in EEG during induction of propofol anesthesia [4].

\section{Conclusion}

A spontaneous, spatiotemporally chaotic state-generated by nonlinear Turing-Hopf interaction-is the underlying mechanism for the slow oscillation observed in general anesthesia. A similar transition to low-frequency chaos may also occur in natural nonREM sleep, and if so, may have significant implications for synaptic downscaling and memory processing hypothesized to occur during deep sleep.

\footnotetext{
Author details

${ }^{1}$ School of Engineering, University of Waikato, Hamilton 3240, New Zealand. ${ }^{2}$ Waikato Clinical School, University of Auckland, Hamilton 3240, New

Zealand.
}

Published: 16 July 2012
References

1. Steriade M, Nuñez A, Amzica F: A novel slow ( $<1 \mathrm{~Hz}$ ) oscillation of neocortical neurons in vivo: depolarizing and hyperpolarizing components. J Neurosci 1993, 13:3252-3265.

2. Timofeev I, Grenier F, Bazhenov M, Sejnowski TJ, Steriade M: Origin of slow cortical oscillations in deafferented cortical slabs. Cereb Cortex 2000, 10(12):1185-1199.

3. Sanchez-Vives MV, McCormick DA: Cellular and network mechanisms of rhythmic recurrent activity in neocortex. Nat Neurosci 2000, 3(10):1027-1034

4. Koskinen M, Seppänen T, Tuukkanen J, Yli-Hankala A, Jäntti V: Propofol anesthesia induces phase synchronization changes in EEG. Clin Neurophysiol 2001, 112(2):386-392.

doi:10.1186/1471-2202-13-S1-F3

Cite this article as: Steyn-Ross et al:: Chaotic dynamics underpins the slow oscillation of general anesthesia and nonREM sleep. BMC

Neuroscience 2012 13(Suppl 1):F3.

\section{Submit your next manuscript to BioMed Central and take full advantage of:}

- Convenient online submission

- Thorough peer review

- No space constraints or color figure charges

- Immediate publication on acceptance

- Inclusion in PubMed, CAS, Scopus and Google Scholar

- Research which is freely available for redistribution

Submit your manuscript at www.biomedcentral.com/submit
C Biomed Central 